\title{
Perception About Oral Health and Its Determinants in Women in Context of Prostitution in Medellín (Colombia): Expressions of Social Vulnerability
}

\author{
Alejandro Vásquez-Hernández ${ }^{1}$, Carolina Zapata-Villa ${ }^{1} \&$ Andrés A. Agudelo-Suárez ${ }^{2}$ \\ ${ }^{1}$ Faculty of Dentistry, University Foundation “Autónoma de las Américas”, Medellín, Colombia \\ ${ }^{2}$ Faculty of Dentistry, University of Antioquia, Medellín, Colombia \\ Correspondence: Andrés A. Agudelo-Suárez, Faculty of Dentistry, University of Antioquia, U de A. Calle 70 No. \\ 52-21, Medellín, Colombia. Tel: 57-4219-6741; Fax: 57-4219-6700. E-mail: oleduga@gmail.com
}

Received: February 2, 2018 Accepted: March 22, 2018 Online Published: March 24, 2018

doi:10.5539/gjhs.v10n5p42 URL: https://doi.org/10.5539/gjhs.v10n5p42

\begin{abstract}
Background and Objective: Women in context of prostitution (commonly called sex workers) are considered a vulnerable group due to their precarious employment, abuse and exploitation. This study aimed to understand the knowledge, practices and social representations about the oral health component for the health-disease process and its determinants in this group.
\end{abstract}

Methods: A qualitative study was conducted by means of 12 semi-structured interviews in women $\geq 18$ years of age who are dedicated to the act of prostitution. In addition, three interviews were conducted with leaders of projects and/or social organizations within Medellin who work alongside sex workers. The information was analyzed using the Atlas.Ti 6.0 software by identifying meaning codes and grouping in emergent categories.

Results: The analysis of the interviews allowed to establish categories related to oral health and quality of life, social determinants and accessibility to health care. The concept of oral health is related to their self-perception of hygiene and the aesthetic appearance. They relate the concept of quality of life to meet basic needs such as food, housing, health, education, and have a decent job. The economic, political and social context in which they are located affects the quality of life. They identify barriers to access to oral health services, although much of these women recognize their lack of compromise when they need to seek health care.

Conclusions: The oral health and its determinants as perceived by the people interviewed is a true reflection about the situation of social vulnerability of the women in context of prostitution.

Keywords: prostitution, oral health, social vulnerability, quality of life, health services accessibility

\section{Introduction}

Women in context of prostitution (commonly called sex workers) are considered as a special vulnerable social group. Street sex work is a phenomenon that can be explained as a multifactorial social fact and as a productive activity that clearly reflects the need and the search for subsistence of this conglomerate of people, as well as another segment of individuals who reach this activity with the desire to access to goods and social services (Belza et al., 2004; Colombia. Ministerio de la Protección Social [Ministry of Social Protection], 2008). Specifically in the city of Medellín (the second city of Colombia), there are no exact figures on the magnitude of this social phenomenon. The last census dates 1963, although the projections refer to about 25 thousand people framed in this context for the year 2010 according to the information extracted from the press (Ospina Zapata, 2010).

This group is inclined to express a burden of disease by its constant exposure to risk factors for the job they perform (Amaya, Canaval, \& Viáfara, 2005). This is expressed in inequitable conditions in general, marked by marginality and the consequent violations of their human rights, economic precariousness, social insecurity, lack of access to education, social exclusion, domestic violence, sexual abuse, child abuse, lack of labor rights and other social problems that coexist such as violence, drug abuse and alcohol that are responsible for the increase of sexual transmitted diseases (Belza et al., 2004; Ribando, 2008).

Although scientific research has been concerned with the study of social inequalities -unfair and avoidable differences among population groups- (Commission on Social Determinants of Health. World Health Organization 
(WHO), 2008), oral health studies in these women are scarce. This was manifested in an recently published Scoping Review (Vásquez Hernández, Vivares-Builes, \& Agudelo-Suárez, 2016), where only 10 studies were found with relation to systemic diseases and HIV, access to health services, practices against the use of condoms and only a specific study (in methodological terms) which evaluated the periodontal situation in sex workers in Senegal (Ndiaye et al., 1997). Considering that oral diseases are constituted as public health problems in terms of magnitude, severity and quality of life of the people which affects, for dentistry, is a challenge, the study of inequalities and inequities in specific population groups in order to establish policies and strategies according to social reality (Agudelo Suárez \& Martínez Herrera, 2009; Petersen \& Kwan, 2011).

Qualitative studies have enjoyed increasing interest in the dental field (Stewart, Gill, Chadwick, \& Treasure, 2008). This allows to have elements that account for social phenomena such as understanding the experience of being a woman in prostitution situation and with unsatisfied oral health needs ranging from education to care. Likewise, this constitutes as an input for the studies development of greater scope and depth that account for the oral health situation and the factors that affects and modify.

With the support of two Universities in the City of Medellin, a project was developed with the use of different methodologies (quantitative and qualitative) that allow a comprehensive approach of this phenomenon with the general objective of analyzing the oral health status of Medellin sex workers and their related factors. Taking into account the above, the objective of this study was to understand the knowledge, practices and social representations of the oral component of the disease health process and its determinants for this group.

\section{Methods}

\subsection{Design, Study Context and Participants}

An inductive, interpretative, and emergent study was conducted with an ethnographic perspective. This design allowed for the study of ideas, beliefs, meanings, patterns, behaviors and the deeper description of a culture of a community (Vázquez et al., 2011). This was done with the purpose of describing and analyzing daily activities in the face of health and illness phenomena and how they attribute meanings to oral health practices.

The geographical context for the elaboration of the study was constituted by the city of Medellín and its metropolitan area (municipalities and localities nearby). Participants were defined as women in prostitution who were of legal age ( $\geq 18$ years old). Although in many writings and publications people talk about sex workers or prostitutes, the research group chose to denominate this group like women in "context or situation" of prostitution, after initially contacting different leaders of organizations working with this population, who recommended this definition with the aim to use a less derogatory language.

In order to attract this population, governmental organizations and organizations working with these women were used. On the other hand, field visits were made to a sector of the center of the city characterized by a great influx of bars and discos and night clubs where these women are traditionally located. There were also promotional campaigns and oral health education in social organizations and in the street. Finally, snowball was used through women referred by the participants themselves.

The sample of participants according to the qualitative design was defined by intentional or theoretical sampling (Vázquez et al., 2011). Sufficient and in-depth information was gathered to describe in detail the situation under study. Twelve (12) women participated, whose sociodemographic characteristics are described in Table 1. The saturation criterion was sought as much as possible, noticing that no new information was being perceived by the study participants. It is important to mention that security reasons in some areas of the city, and the fear of many women to be interviewed were reasons for the work field to be affected to some extent. Additionally, 3 leaders of organizations of the city were interviewed.

\subsection{Techniques and Tools for Collecting Information}

Fieldwork was carried out between July 2014 and July 2016. Interviews were conducted with semi-structured depth of character, allowing the exchange of ideas, meanings and feelings about the world and its events, in an interaction in which different realities and perceptions are explored. A question guide was established by the research group based on previous studies (available if a request is made to the authors). To facilitate the development of the interviews, it was previously agreed with the study participants, the date and time of the meeting, in a place that would guarantee confidentiality and comfort. At the request of the participants, it was decided that the interviews will be conducted only by the women of the research group $(\mathrm{CZV})$, because of the sensitivity it could cause in women and to guarantee a climate of confidence and tranquility.

Additionally, in order to understand the social context of women, during the recruitment period of the women some 
observation of relevance notes were made for the analysis of the interviews and the discussion of results. In relation to the interviewed leaders, the interview guide was similar since it pretended to know the point of views on women in the context of prostitution while enriching the analysis.

Table 1. Sociodemographic description of women in prostitution context participating in the study. Medellín, 2014-2016 ( $\mathrm{n}=12)$

\begin{tabular}{ll}
\hline Characteristics & N \\
\hline Age & \\
$20-40$ & 5 \\
$41-60$ & 5 \\
$61-80$ & 2 \\
\hline
\end{tabular}

\section{City of Birth}

Medellín

Other zones

Performs other occupation or job

Yes

No

Affiliation to Health Social Security

Yes

Education Level

$\leq$ Primary

Secondary

Important oral diseases

\begin{tabular}{ll} 
Yes & 8 \\
No & 4 \\
\hline Total & $\mathbf{1 2}$ \\
\hline
\end{tabular}

\subsection{Data Analysis}

The interviews were audio-recorded in mp3 and transcribed literally in Word for later analysis. An initial reading of the data was made and the data was manually segmented, identifying eloquent fragments, attributing meanings to later make a narrative analysis of content (Taylor \& Bogdan, 1987; Vázquez et al., 2011). Later, the information was analyzed in Atlas.Ti version 6.0 (Puig, Baños, \& Esteban, 2014). A hermeneutical unit was created where they identified codes to which different meanings were attributed, 11 categories of analysis were defined ( 2 of these are common for both types of study participants). This allowed the elaboration of content matrices, generating mixed categories; those established initially by consensus of the research group and other emerging ones of the participants' speech. The analysis was carried out by the three researchers in joint meetings for standardizing the categories and codes found. The results are differentiated by actors (leaders and women in prostitution).

The study of the perceptions of the participants of the study, was approached from an anthropological perspective that according to the author Luz Maria Vargas (1994) is the form of behavior that comprises the process of selection and symbolic elaboration of the human experience, which have as limits the biological abilities and the development of the innate quality of the man for the production of symbols. Perception attributes qualitative characteristics to the objects or circumstances of the environment, through referents that are elaborated from specific cultural and ideological systems, built and rebuilt by a social group, which allows to generate evidences on the reality (Vargas Melgarejo, 1994).

It is important to keep in mind that the qualitative perspective assumes some criteria to guarantee the quality in the 
collection of the information, and in data analysis that are alternative to quantitative research given its epistemological perspective. Triangulation was used to compare the results with different sources of information both primary and secondary, as well as with the discussion of the researchers and participants in the process; and quality criteria were guaranteed such as epistemological adequacy -quality in the problem formulation and methodological coherence, understood as: the direct relationship between questions, objectives, techniques and procedures-, the validity of the data and its relevance in the social context and reflexivity -leading to a better description of the social world, to the extent that the perspectives and points of view of the research group were made explicit- (Calderón, 2002; Sandoval, 1997).

\subsection{Ethical Aspects}

Fulfillment with the ethical requirements for research in humans was guaranteed according to national regulations (República de Colombia. Ministerio de Salud y Protección Social [Republic of Colombia. Ministry of Health and Social Protection], 1993) and international (World Medical Association, 2013). It is important to mention that this population is sensitive, therefore confidentiality was kept and prudence in the management of the information collected in the interviews, taking into account the nature of qualitative research (Galeano, 2004). The protocol that gave rise to this research was approved by the Ethics and Bioethics Committee of the University Foundation "Autónoma de las Américas" (Act 001/2014).

\section{Results}

The results found allowed to reveal the situation of oral health and the determinants that affect it from the own women perspective who daily perform prostitution, as well as the social context and opinion of leaders working in key organizations.

\subsection{The Perspective of Women in the Context of Prostitution}

\subsubsection{Concept and Recognition of Their Oral Health Situation}

Among women in prostitution the concept of oral health is rooted in the traditional concept of associating it with hygiene habits and the cosmetic appearance of teeth. Well-being from the oral component is also related to the possibility or not, of accessing the usual supplements of oral hygiene (Table 2: 1a, 1b).

A large part of the participating population recognizes the deterioration of their oral health and the need for treatment, as well as admit not having the commitment to seek care (Table 2: 1c, 1d, 1e). Similarly, in several of the women's stories, they perceive a relationship between deterioration of their oral health and the exercise of prostitution (Table 2: 1f).

The environment of prostitution favors practices such as the consumption of alcohol and psychoactive substances that are determinant in the deterioration of oral health. Mediation either voluntary or compulsory (required by customers) of elements that induce harmful behaviors of drug use were common in the context of prostitution. There was a general perception that the consumption of hallucinogens associated with poor hygiene practices accelerates the process of tooth destruction (Table 2: $1 \mathrm{~g}, 1 \mathrm{~h}$ ).

\subsubsection{Concept of Quality of Life}

Quality of life was defined as a broad set of factors that express the tranquility of being able to enjoy certain rights that allow us to consolidate stability as a family. In this concept access to health education and decent employment was explored, but in addition they refer to the importance of meeting basic needs such as food and shelter (Table 2: $2 \mathrm{a}, 2 \mathrm{~b}, 2 \mathrm{c})$.

Women who are immersed in sex work report feeling deprived of quality of life as a result of multiple vulnerabilities to which they are subjected. It was common in the stories of the participants that they were tacitly obliged to take on harmful behavior such as working all night long, alcohol consumption, ingest psychoactive substances and in addition to accepting sexual partners that are not of their choice but the obligation of the necessity that comes with the context of prostitution. It is important to mention that in the speeches obtained from the participants, no one reports being in prostitution by choice of pleasure or an easy link to material consumption. Their choice has to do with deep unmet basic needs that surround them and their families (Table 2: 2d, 2e).

The exercise of prostitution guarantees them access to money -whether little or much in quantity- and it is this one that allows them to obtain the support of their families. Money is the representation not of access to sumptuousness and excesses, but rather the approach to providing the minimum of economic stability for those close to them. The remuneration achieved is the constant contradiction of the women in exercise because this money comes from a practice that generally causes frustration and pain, but they admit that to have some quality of life shared with the family it is necessary to continue. In much of the speeches, the family is the reason that moves the exercise of 
prostitution in spite of the misfortunes brought about by this trade (Table 2: $2 \mathrm{f}$ ).

\subsubsection{Oral Health and Its Relation With Quality of Life}

They recognize oral health as an important part of quality of life. The correlation of the participants with the worsening of their oral health conditions due to the exercise of prostitution is found in several stories. Concurrences in speeches the perception that for the exercise of prostitution is important to have dental structures in good condition as this is part of an integral quality of life (Table 2: $3 a, 3 b$ ).

Free access to oral health services and unrestricted dental procedures reflects a category of quality of life related to significant oral health for the women interviewed. The limitations in the Plan of Benefits in the General System of Social Security in Health (SGSSS- Acronym in Spanish) in the treatments offered from the buccal component and the high cost of the particular procedures, prevent people from being able to solve their needs according to their personal expectations. Being able to smile spontaneously and with healthy teeth is for them a possibility of freedom (Table 2: 3c, 3d).

\subsubsection{The Mouth as an Instrument of Work}

Some women in situations of prostitution identify the mouth as an instrument of work that is to say without any restriction they perform sexual practices complementary to the genital practices. Others and deepening beyond the sexual exercise, give a wide, reserved and intimate meaning to the sexual practices that are performed with the mouth.

The mouth is a space of enjoyment that is reserved exclusively for love and preserves and cares for, as such. Therefore, although some recognize the possibility of having sex from the intimate space that is their mouth and some accept to kiss under the conditioning of their work, others report being in complete disagreement mediate sexual practices with it because it is the only context that they admit, they can enforce in their temporal dimension of prostitution (Table 2: $4 \mathrm{a}, 4 \mathrm{~b}$ ).

The knowledge of contagion of sexually transmitted diseases through the mouth is limited and returning to the previous category on education, their knowledge is framed in the myth precisely because health education is often in charge of the same women who are in prostitution situation.

In general they recognize the use of condoms as a barrier to protection against many types of diseases, but it is clear that it is a restricted knowledge that does not diminish many other risk behaviors among this population. They admit that sometimes the risk of unsafe practices without a condom is assumed to receive a higher rate for their service or in other cases, when they recognize their customers as "acquaintances" (referring to their subjects who usually contact them), they accept not using elements that are barriers to contagion (Table 2: 4c, 4d).

\subsubsection{Self-Care and Oral Hygiene Practices}

They identify that in order to preserve good habits of oral hygiene it is essential to practice self-care, which generates the motivation of having a "clean and fresh mouth". They report that despite having very clear what kind of bad oral practices represent something they define as "bad smell", hardly in that context can have a negative from a client and end up giving in to the explicit need to want to work to survive (Table 2: 5a, 5b).

They recognize having craft practices on oral health and these are reflected in their habits associated with the fear generated by the assistance to the dentist. They admit in several speeches never to have received education in oral health and to have limited knowledge about self-care (Table 2: 5c).

\subsubsection{Access to Oral Health Services: Barriers and Conditions}

An important element of the analysis of interviews is related to the knowledge that women in prostitution have about their rights in health. They claimed to have limited knowledge on this subject. Although there are different city programs that have the objective of training them, for them the concept of law and health is still limited to the biological complex and administrative access to schedule an appointment (Table 2: 6a). This same situation is evidenced when the interviewees recognize that the knowledge about their right to oral health is limited to information about access to dental consultation. They do not recognize any type of law related to oral health.

Several women identify barriers to access dental appointments such as: delayed appointments, lack of availability of professionals, difficulties in communicating with the entity providing the service and extensive procedures for accessing care among others (Table 2: 6b, 6c, 6d).

They perceive that the problems of deterioration in the buccal component are the general reflection of the deterioration of the health, associated by some to the neglect of their living conditions, not precisely for exercising prostitution. They admit that their real context of inequities ends up diminishing their ability to demand access to 
dental consultations; however, some from their limited economic capabilities finance their dental treatments, precisely because they emphasize the importance of meeting their needs despite adversity (Table 2: 6e, 6f, 6g).

\subsubsection{Discrimination as a Social Determinant of Health and Oral Health Inequalities}

The discrimination for this group of women is the signaling, stigmatization and victimization of a person due to their work or some type of behavior (Table 2: 7a, 7b). They recognize that discrimination is a social burden that must coexist because of the way they earn a living. They assume that although discrimination is not a constant in the use of health services, they report that some professionals in the field have discriminated against them because of the job they perform. Many of the participants prefer to omit or lie about their profession for fear of being discriminated against in different spaces, including health services (Table 2: 7c, 7d).

Social and common scenarios to this population is that they are marked by their job when they try to perform another type of work. They report experiences of discrimination in which ordinary people assume behaviors from them associated with theft, bad life, risk behaviors. Discrimination comes from multiple sources, including family members (Table 2: 7e, 7f).

Finally, some women in this population recognize discrimination as a reality that can be reported to the authorities. They perceive discrimination as socially and legally intolerable behavior.

Table 2. Textual quotations of women in the context of prostitution on oral health and its determinants. Medellín, 2014-2016 ( $\mathrm{n}=12)$

\begin{tabular}{|c|c|}
\hline Categories & Literal quotations of the participants \\
\hline \multirow{8}{*}{$\begin{array}{l}\text { Concept and } \\
\text { recognition of } \\
\text { your oral } \\
\text { health }\end{array}$} & $\begin{array}{l}\text { a) "For me, oral health is very important because the oral health in a person is like the letter of } \\
\text { introduction, because if a person does not have good oral health, then he has nothing. Oral health, } \\
\text { as I say it is the cleanliness of the dental part, the cleanliness of all my pieces that I have as a human } \\
\text { of my teeth" TS3 }\end{array}$ \\
\hline & $\begin{array}{l}\text { b) "Oral health for me is to have all the teeth in good shape, all good, maintaining the hygiene of the } \\
\text { brushing, dental floss, the Listerine as one often can afford them other times cannot" TS8 }\end{array}$ \\
\hline & $\begin{array}{l}\text { c) "I need to fix these two teeth, that black tooth, I'm worried about this other one which wants to get } \\
\text { black which I think it has that root canal treatment, many years ago I did it, I'm worried it's the } \\
\text { appearance that I cannot laugh with ease" TS8 }\end{array}$ \\
\hline & d) "Ifeel regular because I lack teeth and some work that I have to do in the dentures" TS9 \\
\hline & $\begin{array}{l}\text { e) "They are not interested in taking care of anything, I said to Andrea, Andrea come on let's go she } \\
\text { told me to take a girl and Andrea has these teeth here broken and missing, she doesn't care." TS12 }\end{array}$ \\
\hline & $\begin{array}{l}\text { "Yes, due to what I used to do, that I did blame, because the teeth starts to disfiguring, they start to } \\
\text { loosen, I blamed prostitution" TSI }\end{array}$ \\
\hline & $\begin{array}{l}\text { g) "Yes, you can see that a lot, the alcohol, the drug and many times for example men that wants you to } \\
\text { do drugs when you go with them, maybe if they go like that they want you to do the same, that is } \\
\text { when it occurs and you do not want to it will go wrong, so that is why" TS8 }\end{array}$ \\
\hline & $\begin{array}{l}\text { h) "The cigarette and the liquor damage the dentures and besides from that the carelessness of one, of } \\
\text { not maintaining the oral hygiene of brushing } 3 \text { times a day at least, that influences a lot" TS8 }\end{array}$ \\
\hline \multirow{4}{*}{$\begin{array}{l}\text { 2. Concept of } \\
\text { quality of life }\end{array}$} & $\begin{array}{l}\text { a) "In my life, quality of life is being able to live better from what I am currently facing. For example, } \\
\text { you cannot have a good quality of life if you do not have a job, you cannot have a good quality of life } \\
\text { if you do not have the things you need. If I have good health I have a good quality of life, if I have } \\
\text { good food, I have a good quality of life, but If I have no health, If I do not have food, or a way to go } \\
\text { to the doctor I have a poor quality of life" TS4 }\end{array}$ \\
\hline & "Quality of life is having access to health, education and good treatment" TS7 \\
\hline & $\begin{array}{l}\text { c) "For me, quality of life is having a roof, not much luxury, but a good roof, have a job and a family, } \\
\text { having the funds to afford basic needs and try to grow in the education part" TS8 }\end{array}$ \\
\hline & $\begin{array}{l}\text { d) "The quality of life of us who do this bad job, because we have to go through to staying up all night, } \\
\text { we have to drink alcohol, we have to go through, even if we do not like it, drugs, so the quality of life } \\
\text { of the people in context that practices this job is very bad" TS3 }\end{array}$ \\
\hline
\end{tabular}


e) "Oh no you do not have a good quality of life in prostitution, one does it because one had to as they say, but that is not quality of life, one has to sleep with a man that one does not want to" TS4

f) “... I earned money and I knew I would get home to give it to my kids what I could, I paid my debts, I paid my rent. I do not want to be in this life anymore, I do not want to enforce prostitution, so I earn more not wanting to do this, then continuing” TS3

a) "Yes mami, but regarding quality of life... well now, thank God from that no weird diseases were transmitted, when you say compared to health, yes, the only thing I lost due to my way of life, the only thing I lost was my denture because it was precious, not anymore”. TSI

b) "It is very important because if I have oral health I have a good quality of life for my job, for all the sectors in which I move” TS4

3. Oral health

c) "Quality of life related to oral health is being able to have access to the health entities without so many restrictions, without many problems, without the "but" that they always give for many things,

and its for example I always wanted to fix my mouth ¿right? as I was saying I am embarrassed about this relation to quality of life black tooth, with this tooth like this, but see it is expensive, I went to SURA and they told me: "no, it is only the basic no more, the other will have to be private" and private is very expensive and one does not have the possibility of saying: "it would be great to do a smile design, I am going to get fixed" because one would feel embarrassed because one feels bad when one cannot smile with freedom, for example just like you smile, it is not the same" TS8

d) "I need a plate but a protective plate, and the health center does not pay for it, if I do not have the money to pay for the plate private I have to eat my teeth, complete eating my teeth that is to not have the quality of oral health because I have no way to pay for the plate that I need" TS7

a) "Not only a prostitute makes love by penetrating the man the vagina, but there are also women who have allowed the men to make love to them by the mouth" TSI

b) “No, I do not Kiss anyway, that I know for sure” TS10

4. Mouth as an instrument of work

c) "Yes, I do oral sex but with the condom and depending on the client, because if it is a good steady client and I know that it has been that way with him then yes, but if it is another one that does not use condom or anything, no papi we cannot go to the piece, but yes very hard. Protection for everything, because the teeth can hurt, bad smell catches on my mouth and everything" TS12

d) "I will suck but with condom, but without the condom no my love because I do not know you, I don't know who he is or where he is from, or where he came from, or where he will go to... no my love, but for me to earn more money I will do it” TS10

a) "My previous habits were not as good, that is I did not brush my teeth very often, let's say that now I am brushing about 3 or 4 times and I am using dental floss more often, I do not lack Colgate, sometimes I do take long to change the brush, and I sometimes can afford to buy Listerine, so it is a

5. Self-care and good health, maintaining the mouth fresh, clean" TS8

oral hygiene b) "No, I used to care less, I only cared to maintain the mouth clean, that it did not smell bad because it practices would be embarrassing with the client, althought we had some clients that no, I could not go near by them because they had a Monster, so it would get disgusting but I had to take them." TS7

c) I would have to learn more, because regarding oral health I do not have any knowledge, as I mentioned, I am afraid of dentistry, so I would like to learn more" TS3

a) "They told us we had the same rights as any other person, and those rights could not be denied and they told us the same rights, that we not could allow them to discriminate us that we were a person as any other, and foremost when a person has an advanced disease they have to be a priority, since

6. Access to oral health services: Barriers and conditions serving them first for example if I have a Disease that is venereal they must serve you first or AIDS, other people like this who have money or whatever, they must serve you first, we were taught and they informed us there, I am in the list for my rights" TS9

b) "For me it has been very bad, because for me to be able to schedule a dentist appointment, for you to be able to get them to see your teeth is very hard, because if you get an appointment, you will get it for 2 or 3 months later, so that has been a hard subject” TS3

c) "I went to COMFAMA (health institution), to the SISBEN (social institution) and to the health center to see if they get me an appointment and they informed me that no, that I needed to wait for 
the SISBEN for me to be able to get an appointment, very complicated" TS4

d) "For the dentist the telephone was always busy" TS7

e) "That we have no health, because many women who do prostitution are very careless, not just because they are in prostitution, but also the lack of space or time to get an appointment with the SISBEN, they don't do it, that is why it always happens" TS3

f) "The principle barrier is one who wants to, if I want to live this way and even if I do not have the money I can probably get it in any way, and you can start depositing little by little until you get the job done, but nothing is impossible in this life as long as one wants" TS9

g) "Yes, I was in the emergency room one day and they treated me some grinders, and they were going to continue the treatment but I never went back" TS10

a) "Discrimination is like classifying a person, how to select them, how to stigmatize that is to never treat them like any other person, that is" TS8

b) "For me discrimination is that one person is left out just because of an event or something they do, that is for me discrimination" TS3

7. Discriminatio

n as a social determinant of health and $e$ ) oral health inequalities c) "Yes, a dentist discriminated her, He said: do not be disgusting that you cannot do that" TS1

d) "Oh yes, one went to get an appointment and they looked at you badly, they gave you the appointment with anger, but it's Ok one knew that could be possible” TS4

"If felt very discriminated in my family with my mother, with the friends, well the friends from school used to say. ¿Why? Because they no longer see you as the same girl as the same young lady, but they looked at you as a prostitute” TS4

f) "There are jobs that one is not accepted because one supposedly comes from bad habits, like robbery because in prostitution sometimes robbery is done, drugs are taken that is many factors that are done in that environment, so there are people who refuse to be with you because they think you are a theft, that you are not good enough to be with this person, so that is why one feels discriminated" TS7

\subsection{The Perspective of the Leaders}

\subsubsection{Scope of the Concept of Sex Work}

As the leaders are asked about the concept of sex worker they express that through the work of organizations it is the same women who have come to the conclusion that their job cannot be circumscribed within the concept of work. For this it would be necessary to comply with the legal minimums of a job: permanent pay, social security affiliation, decent conditions and labor rights to perform their job and these conditions do not exist for the population in context, therefore they prefer to be identified as women in prostitution.

While being "so-called sex workers" exhibits a status that in their point of view may be less demeaning than being called "whores or prostitutes" in the everyday life, none of these concepts can explain the true circumstances under which prostitution is practiced. Revised the new sociological concepts emanated from the work with this community, it is assumed with more naturalness and respect on the part of the organizations and the citizenship to name them as women in situation of prostitution since it corresponds to the social representations that have previously been portrayed by them in the different qualitative investigations that have given a step to other views (Table 3: 1a).

\subsubsection{Protection and Defense of Women in Context}

The importance of the organizations that work with this population, is their fight decided by the recognition of the women in situation of prostitution. Women attend these institutions in the search for recognition as citizens and citizenship implies recognizing themselves as subjects of law. Those who attend these types of institutions do not necessarily have a definite purpose of abandoning or remaining in prostitution, the main achievement of these projects is to strengthen in women their capacity in the enforceability of the right and their right to be or not to be in a situation of prostitution. It is not the choice to remain or not to remain in the job the main objective of the institutions, it is the capacity for self-determination and the way in which it is conceived, how it is performed and how it is cared for itself in the right to exercise any job (Table 3: 2a).

3.2.3 Concept and Recognition of the Oral Health Situation of Women in the Context of Prostitution 
The concept of oral health continues to be focused on the notion of tooth care and aesthetics. The traditional concept that they express is the same limited concept that is transmitted to the populations with which they work and in a certain way marks the little valuation that is given to the integral care of oral health. Although some recognize the importance of communication and orality as a way of assuming myself in front of others, it is clear that the aesthetic part and personal presentation before society continues to be marked as a discourse. The notion of well-being based on the absence of tooth pain is reinforced (Table 3: 3a, 3b, 3c).

For leaders in some cases the need for oral health for women in prostitution is unknown. In their point of view, women never express concerns, discomfort or needs from this component (Table 3: 3d, 3e). However, other discourses of the leaders express the precarious quality of life that women have due to poor oral hygiene, they also find that the unsatisfied needs from the oral component are wide since they cannot access surgical treatments, prostheses for dental losses, extractions or simply screenings. It is common to observe unfinished dental treatments or in very poor conditions that date back many years (Table $3: 3 \mathrm{f}, 3 \mathrm{~g}$ ).

Another problem that adds to the vulnerability of their oral health conditions is the consumption of alcohol and psychoactive substances that worsen their situation; it is common in them that because of the excessive consumption of substances they remain many days without performing the proper oral hygiene and they do not know the whole protocol of self-care to have well-being in their mouth. On the other hand, in the context in which these women develop their job or daily life, there is physical violence that generates multiple trauma and fractures in the teeth which are not solved by the lack of access to services but also by the lack of introjection about personal care concepts that they care less about their needs (Table 3: 3h, 3i).

\subsubsection{The Mouth as an Instrument of Work}

Leaders perceive that there is more taboo over conventional sexual practices (genitality) than having sexual practices with the mouth. Oral sex is a normal practice that is discussed as such without any restriction by women in this context (Table 3: 4a).

Table 3. Textual quotes from leaders about women in the context of prostitution. Medellín, 2014-2016 ( $\mathrm{n}=3$ )

Categories
a) "This had an analysis of why not prostitute, why not whore, why not sex worker and why not in
situation of prostitution. We concluded with themselves that the term where they were most
identified was in the exercise of prostitution, the exercise of, a job that is prostitution, an activity
that is prostitution, not sex workers because they are not in a situation of any worker, they are not
affiliated to social security, they are not in decent working conditions, they do not receive their
remuneration every month, so that is not a job. Work is when they are in those functions but that
is not a sex worker, although some of them, we have noticed, are identified with the name, if you
ask her she says: I am a sex worker, because in some clear way, it is a less exclusive name for you
to say: I am a whore, or I am a prostitute. So that somehow gives it a different status, but it is not
because they feel identified as sex workers, because they are not" L1

2. Protection and defense of women in context a) "It is important that they recognize themselves as women subject to law, independent of the job, they do not come to Women's Spaces to leave prostitution; They come to Women's Spaces to be recognized as a subject of law, independent of the job. Many of them want to stop prostitution and go into a process to leave prostitution, but many of them will never leave it it's also their right to be practicing a job" $L 2$

\section{Concept and} recognition of the oral health situation of women in the context of prostitution a) "Well oral health is hygiene, care, use brush, floss, go to permanent controls of the mouth" L1

b) "The oral health for me is super important, for me is the presentation, because when I go to someone and I hope that this person speaks to me, I will undoubtedly look at his mouth because through his mouth is that we communicate, is how we look at each other, the mouth is very important, so important in order to feed, as well as to be able to express what you have in your head" $L 2$

c) "For me oral health is to have a good care of the teeth, to fulfill their basic function, to serve me to eat, to feel no pain, we associate it a lot also with the image, so that I look good and I feel good with my teeth and with my mouth in general" L3

d) ¿Did you see a need of an oral health program for this type of population? 
e) "No. Because we have not seen it important, they have in no way complained, ever, not even told us they are hurting a tooth, my throat hurts because of my work. We have had a lot of people coming from treats, that in one day they have to attend 20, 30 clients and have to do oral sex, they have never said that they have had problems with their throat, anything, no, we have not seen it necessary. $L 1$

f) "For me it is not very good, there is no good care of its hygiene, because in what one perceives when one has contact with the population basically, not because they manifested it but more likely by what I can perceive... in what I can manage with this population, is not very good, they do not have a good appearance in their oral health"

g) "Very bad, many have prosthetics of 10 or 15 years, which have not been re-examined it or treated and by the consumption of psychoactive substances many have lost their teeth”. L2

h) "That they have several cavities, that they have as I say bad grinders I do not know the technical term in dentistry but here they tell me "I have a bad grinder and it really hurts" "This tooth fell" "I have to rectify the issue with the dental plates" I do not know if the term is correct, but they complain a lot about it because it seems the plates have a maintenance and many of the users never attend to those maintenance. L2

i) "The needs are I believe they would be like from the training because many do not know what is dental floss, one speaks to them of dental floss and they imagine another intimate clothing, also because of intrafamiliar violence that many of them lack pieces of dental, by falls, by hits, because they have been thrown from a second floor and in some cases they lose all their teeth from the top to the bottom, also due to the excessive consumption of bazuko or another type of drug that damage all the oral health and the essential thing is that they are not aware that the mouth is an organ that must be taken care of daily, so they do not have that sense that the mouth must be brushed daily 3 times a day, no, they do not have that internalized that aspect that is so important as bathing, they bathe at least once a day, but they do not brush their mouth, so they drink alcohol, they smoke cigarette, they do drugs and two, three days or four days passes by without brushing their teeth because to them it is not as important" L2

a) "No, we do not believe, because one works with them in a healthy way, it is only us and we have peace besides we hardly touch the subject and cannot imagine what type of subjects we discuss as for example with them, that it is much more a taboo the sexual part that the mouth for example regarding relationships, regarding what clients ask for and we openly touch the subject and discuss it and there has not been any taboo subject. There is no taboo on... for example we talk about oral sex a lot" $L 1$

\section{Discussion}

The findings found in the present investigation are related to the oral health situation and the factors determining it in women in the context of prostitution in the city of Medellín, from the interviewees' own experiences, as well as from the perception of key players in the process that these women face day after day. The oral health situation in general terms is perceived as an expression of the situation of social vulnerability in which these women are.

The quality of life and its relationship with general and oral health is revealed as a multidimensional element, which is related to elements of the social and political system where these women are inserted (Schwartzmann, 2003). For interviewees, a poor quality of life is perceived and this is determined by their current social conditions and their employment situation, understood from the conditions of employment and work. The people who pursue prostitution are facing a situation of precarious work, which has been defined in the literature as a complex conceptual construct and that has been adapted to these women, it is manifested in characteristics such as instability in employment, low capacity for empowerment, vulnerability of their working conditions (situations of abuse and labor exploitation, not having a work contract and social security), the low salary level with which they cannot meet their basic needs, the absence of social benefits, the non-capacity to exercise their rights and the low level of associationism and social participation (Amable, 2006).

The study participants recognize oral health as an important element to obtain quality of life, which is defined from the habits of self-care and the aesthetic appearance of the teeth. However, they recognize that their oral health is impaired and that they require attention. This is explained by the existence of determinants of health and access related to the labor conciliation that constitutes a factor that is unfavorable to adherence and/or continuity to dental 
treatments and in the personal and oral self-care practices that women do; although the literature recognizes that women consult health services in greater proportion and in some cases have better oral hygiene practices than men (Fukai, Takaesu, \& Maki, 1999; Miranda \& Peres, 2013).

Access to oral health services is an intermediate determinant of health inequalities in populations considered to be socially vulnerable (Rocha-Buelvas, 2013). The reverse care law conceptually expresses how the populations that require the most care are those who receive the lowest health care (Hart, 1971). Although women in the context of prostitution know that they are entitled to dental consultation, they face barriers related to the infrastructure of health services to provide care (availability of professionals and appointments), like others related to the system (bureaucratic procedures). The General Social Security System in Health in Colombia is composed mainly of two regimes, one contributory where the persons with capacity to pay belong (mainly working population) and one subsidized for people with no ability to pay. Although this Health System expanded coverage in terms of number of affiliated persons, significant structural problems continue to occur that affect adequate access to preventive and curative health benefit plans (Agudelo Calderón, Cardona Botero, Ortega Bolaños, \& Robledo Martínez, 2011; Guerrero, Gallego, Becerril-Montekio, \& Vásquez, 2011).

Discrimination has been defined as a structural determinant of health inequalities and people who have suffered experiences of racism, sexism or classism are more likely to have health problems (Borrell et al., 2010; Gil-Gonzalez et al., 2014; Simons, Koster, Groffen, \& Bosma, 2016). In the case of women in the context of prostitution, they must face a cumulative vulnerability for being on a smaller scale in the structure of society and gender discrimination. Literature has established how social inequalities or those unjust and avoidable differences have been incorporated into society and that manifest biologically (Krieger, 2001, 2005). There are social groups especially vulnerable that in their history have been accumulating these social inequalities (such as these women) and not only expressed in their general health situation, but are related to their oral health situation, which is constituted as a biological, historical and social product (Abadía Barrero, 2006).

It is important to comment on the strengths and limitations of this research. To the best of our knowledge, this is the first study to analyze the oral health situation and its determinants in the population of women in the context of prostitution in the city of Medellín. Although qualitative studies are not intended to infer results to the general population of women in the context of prostitution, offers the recognition of the social context that influences the oral health situation in these women, from their own expectations, opinions and perceptions. This information will be complemented with surveys and clinical examinations that allow to establish the magnitude and severity of the problem. It is important to mention that this is a sensitive group and that there are difficulties to access them due to their schedules in the exercise of prostitution, security problems and pimping, which are the reflection of the social situation of this type of population.

This study showed the invisibility of this population in terms of studies that characterize and/or allow a real diagnosis of oral health status in women in the context of prostitution. It is therefore vitally important to recognize the right to health of these women as any other population group. Assuming a rights perspective involves analyzing oral health as a component of general health and not as an isolated entity. Therefore, intervention programs must be based first and foremost on the knowledge of the problems and needs of social groups. This is constituted as an input for the generation of policies and strategies that address the social determinants and the reduction of inequalities in health and oral health guaranteeing equitable access to health services for these women and the generation of other social programs.

\section{Acknowledgements}

The research group is deeply grateful to the women who participated in this study and the leaders of organizations for their willingness to collect information; this allowed the knowledge of an important social reality and little known in our environment.

\section{Funding}

University Foundation "Autónoma de las Américas", Medellín, Colombia (Ref: 005-2014) and economic resources provided for the research team.

\section{Competing Interests Statement}

The authors declare that they have no competing interests.

\section{References}

Abadía Barrero, C. E. (2006). Pobreza y desigualdades sociales: un debate obligatorio en salud oral [Poverty and inequalities: an obligatory dental health debate]. Acta bioeth, 12(1), 9-22. 
https://doi.org/10.4067/S1726-569X2006000100002

Agudelo Calderón, C. A., Cardona Botero, J., Ortega Bolaños, J., \& Robledo Martínez, R. (2011). Sistema de salud en Colombia: 20 años de logros y problemas [The Colombian healthcare system: 20 years of achievements and problems]. Cien Saude Colet, 16(6), 2817-2828. https://dx.doi.org/10.1590/S1413-81232011000600020

Agudelo Suárez, A. A., \& Martínez Herrera, E. (2009). La salud bucal colectiva y el contexto colombiano: un análisis crítico [Collective oral health and the colombian context: a critical analysis]. Rev Gerenc Polit Salud, $8(16), 91-105$.

Amable, M. (2006). La precariedad laboral y su impacto en la salud. Un estudio de trabajadores asalariados en España [Precarious employment and its impact on health. A study for Spanish workers]. (Doctoral Thesis), Universitat Pompeu Fabra, Barcelona.

Amaya, A., Canaval, G. E., \& Viáfara, E. (2005). Estigmatización de las trabajadoras sexuales: influencias en la salud [Stigma of sexual worker women: influences on health]. Colomb Médica, 36(3 Supl 2), 65-74.

Belza, M. J., Clavo, P., Ballesteros, J., Menéndez, B., Castilla, J., Sanz, S., . . Romero, J. d. (2004). Condiciones sociolaborales, conductas de riesgo y prevalencia de infecciones de transmisión sexual en mujeres inmigrantes que ejercen la prostitución en Madrid [Social and work conditions, risk behavior and prevalence of sexually transmitted diseases among female immigrant prostitutes in Madrid (Spain)]. Gac Sanit, 18(3), 177-183.

Borrell, C., Artazcoz, L., Gil-Gonzalez, D., Perez, G., Rohlfs, I., \& Perez, K. (2010). Perceived sexism as a health determinant in Spain. J Womens Health (Larchmt), 19(4), 741-750. https://doi.org/10.1089/jwh.2009.1594

Calderón, C. (2002). Criterios de calidad en la investigación cualitativa en salud (ICS): apuntes para un debate necesario [Quality Criteria in Qualitative Health Research (QHR): Notes for a Necessary Debate]. Rev Española Salud Pública, 76(5), 473-482.

Colombia. Ministerio de la Protección Social [Ministry of Social Protection]. (2008). Protocolo del estudio de comportamiento sexual y prevalencia de VIH en mujeres trabajadoras sexuales en cuatro ciudades de Colombia [Protocol for the study of sexual behavior and HIV prevalence in female sex workers in four cities of Colombia]. Bogotá: Ministerio de la Protección Social.

Commission on Social Determinants of Health. World Health Organization (WHO). (2008). Closing the gap in a generation: Health equity through action on the social determinants of health. Geneva: World Health Organization (WHO).

Fukai, K., Takaesu, Y., \& Maki, Y. (1999). Gender differences in oral health behavior and general health habits in an adult population. Bull Tokyo Dent Coll, 40(4), 187-193.

Galeano, M. E. (2004). Diseño de proyectos en la investigación cualitativa [Project design in qualitative research]. Medellín: Fondo Editorial Universidad EAFIT.

Gil-Gonzalez, D., Vives-Cases, C., Borrell, C., Agudelo-Suarez, A. A., Davo-Blanes, M. C., Miralles, J., \& Alvarez-Dardet, C. (2014). Racism, other discriminations and effects on health. J Immigr Minor Health, 16(2), 301-309. https://doi.org/10.1007/s10903-012-9743-y

Guerrero, R., Gallego, A. I., Becerril-Montekio, V., \& Vásquez, J. (2011). Sistema de salud de Colombia [The health system of Colombia]. Salud pública Méx, 53(suppl 2), s144-s155.

Hart, J. T. (1971). The inverse care law. Lancet, 1(7696), 405-412. https://doi.org/10.1016/S0140-6736(71)92410-X

Krieger, N. (2001). Theories for social epidemiology in the 21 st century: an ecosocial perspective. Int J Epidemiol, 30(4), 668-677. https://doi.org/10.1093/ije/30.4.668

Krieger, N. (2005). Embodiment: a conceptual glossary for epidemiology. J Epidemiol Community Health, 59(5), 350-355. https://doi.org/10.1136/jech.2004.024562

Miranda, C. D., \& Peres, M. A. (2013). Determinantes da utilização de serviços odontológicos entre adultos: um estudo de base populacional em Florianópolis, Santa Catarina, Brasil [Determinants of dental services utilization by adults: a population-based study in Florianopolis, Santa Catarina State, Brazil]. Cad Saude Publica, 29(11), 2319-2332. https://doi.org/10.1590/0102-311x00139912

Ndiaye, C. F., Critchlow, C. W., Leggott, P. J., Kiviat, N. B., Ndoye, I., Robertson, P. B., \& Georgas, K. N. (1997). Periodontal status of HIV-1 and HIV-2 seropositive and HIV seronegative female commercial sex workers in 
Senegal. J Periodontol, 68(9), 827-831. https://doi.org/10.1902/jop.1997.68.9.827

Ospina Zapata, G. (2010, 15/04). Desde el 63 no hay censo de prostitución [Since 1963 there is no prostitution census], Opinión. $\quad$ El Colombiano. $\quad$ Retrieved from http://www.elcolombiano.com/historico/desde_el_63_no_hay_censo_de_prostitucion-IWEC_85814

Petersen, P. E., \& Kwan, S. (2011). Equity, social determinants and public health programmes--the case of oral health. Community Dent Oral Epidemiol, 39(6), 481-487. https://doi.org/10.1111/j.1600-0528.2011.00623.x

Puig, M. S., Baños, R. V., \& Esteban, M. P. S. (2014). El análisis cualitativo de datos con ATLAS.TI [Qualitative analysis using ATLAL.TI]. REIRE. Revista d'Innovació i Recerca en Educació, 7(2), 119-133.

República de Colombia. Ministerio de Salud y Protección Social [Republic of Colombia. Ministry of Health and Social Protection]. (1993). Resolución no 008430 de 1993 (4 de octubre de 1993). Por la cual se establecen las normas científicas, técnicas y administrativas para la investigación en salud [Resolution No. 008430/1993 (October 4th, 1993). Scientific, technical and administrative for health research standards are established]. Bogotá: Ministerio de Salud y Protección Social.

Ribando, C. M. (2008). Trafficking in persons in Latin America and the Caribbean. In D. V. Stickle (Ed.), Women's Issues: Economic, Societal, and Personal (pp. 131-150). New York: Nova Science Publishers.

Rocha-Buelvas, A. (2013). Análisis sobre el acceso a los servicios de la salud bucal: un indicador de equidad [Analysis of access to oral health services: an indicator of equity]. Rev Gerenc Polit Salud, 12(25), 96- 112.

Sandoval, C. (1997). Investigación cualitativa [Qualitative research]. Bogotá: ICFES.

Schwartzmann, L. (2003). Calidad de vida relacionada con la salud: aspectos conceptuales [Health-related quality of life: conceptual aspects]. Ciencia $y$ enfermería, 9(2), 09-21. https://doi.org/10.4067/S0717-95532003000200002

Simons, A. M., Koster, A., Groffen, D. A., \& Bosma, H. (2016). Perceived classism and its relation with socioeconomic status, health, health behaviours and perceived inferiority: the Dutch Longitudinal Internet Studies for the Social Sciences (LISS) panel. Int J Public Health. https://doi.org/10.1007/s00038-016-0880-2

Stewart, K., Gill, P., Chadwick, B., \& Treasure, E. (2008). Qualitative research in dentistry. Br Dent J, 204(5), 235-239. https://doi.org/10.1038/bdj.2008.149

Taylor, S. J., \& Bogdan, R. (1987). Introducción a los métodos cualitativos de investigación: La búsqueda de significados. [Introduction to Qualitative Research Methods: The Search for Meaning]. Barcelona: Paidós.

Vargas Melgarejo, L. M. (1994). Sobre el concepto de percepción. [About the concept of perception]. Alteridades, $4(8), 47-53$.

Vásquez Hernández, A., Vivares-Builes, A. M., \& Agudelo-Suárez, A. A. (2016). La Invisibilidad de Estudios en Salud Oral en Mujeres en Situación de Prostitución: Una Revisión Sistemática Exploratoria [The Invisibility of Oral Health Studies about Women in Situation of Prostitution: A Scoping Review]. Int J Odontostomat, 10(2), 287-295. https://doi.org/10.4067/S0718-381X2016000200016

Vázquez, M., Ferreira Da Silva, M., Mogollón, A., Fernández de Sanmamed, M., Delgado, M., \& I, V. (2011). Introducción a las técnicas cualitativas de investigación aplicadas a la salud [Introduction to qualitative research techniques applied to health]. Santiago de Cali: Programa Editorial Universidad del Valle.

World Medical Association. (2013). World Medical Association Declaration of Helsinki: ethical principles for medical research involving human subjects. JAMA, 310(20), 2191-2194. https://doi.org/10.1001/jama.2013.281053

\section{Copyrights}

Copyright for this article is retained by the author(s), with first publication rights granted to the journal.

This is an open-access article distributed under the terms and conditions of the Creative Commons Attribution license (http://creativecommons.org/licenses/by/4.0/). 